and targeting specific economic groups. It sends a powerful signal, particularly to poor and struggling students, that higher education is accessible to all. The rhetoric of "life dreams" establishes a narrative of prosperity based on merit and work, in which higher education plays a critical role.

However, there are important questions about this initiative's sustainability. In principle, the Act allows all Filipinos to access quality tertiary education and commits to "provide adequate funding," potentially establishing universal access. The Philippines has a young and growing population: the number of 15-24 year olds has increased from I7.6 million in 2006 to I9.9 million in 2016 . As the "K-to-I2" transition period ends, more students will be entering higher education. Given the powerful hold of the higher education "dream" among Filipinos, we expect a large increase in entrants into higher education, which may not have been expected when preparing the Act's budget. The absence of a cap on student numbers in the final version of the law confirms an intention to expand the sector, incentivizing SUC leaders to raise revenue by increasing student numbers. This could exacerbate the projected flight of students and faculty from private to public institutions. Thanks to the expanding economy, the Act is affordable in the short-to-medium term. But concerns about a rapid expansion of student numbers call its long-term sustainability into question.

Can the Philippines afford not to introduce such a policy? For the country to compete with its regional rivals as a knowledge economy, expanding access to higher education would likely provide a competitive advantage. With its large service sector and rapid industrialization, the Philippines is well equipped to take advantage of the skilled workforce provided by expanding enrollment in higher education.

DOI: http://dx.doi.org/I0.60I7/ihe.20I8.94.10523

\section{The "Champagne Tower" of Science Publishing}

\section{Sabine Siebert}

Sabina Siebert is professor of management, Adam Smith Business School, University of Glasgow, UK. E-mail: sabina.siebert@glasgow. ac.uk.

ince World War II, there has been an exponential growth $\boldsymbol{N}$ of publications in life sciences. Between the late I96os and 2000 , the number of publications doubled approximately every I4 years, but more recently, the rate has in- creased even further, doubling approximately every I2 years. On the one hand, this growth can be seen as positive in signifying investment in science, especially in emerging economies, which should lead to faster scientific progress. On the other hand, however, the exponential growth of published papers means that journal editors are "flooded" by publications, which they find difficult to process, while scientists find it ever more difficult to keep on top of them. The more science is produced, the more noise in the system, and the more difficult it is for scientists to tell what is trustworthy and what is not. Thus, scientists are increasingly concerned about the ability of the scientific community to control the quality of the increasing flow of scientific outputs.

\section{And, unsurprisingly, open-access jour- nals often charge significant publication} fees.

\section{Scarcity of Publication Space in Top Journals}

In my research funded by the British Academy, I investigated the nature of the overflow in science publications by asking the question: how are paper submissions distributed among journals? Unsurprisingly, I found that publishing in the top-tier journals-Cell, Nature, or Science-appears to be the Holy Grail of science as it guarantees academic positions, grants, and membership on editorial boards. A scientist's career success depends on publishing as many papers as possible in these prestigious journals. Additionally, publishing in the top journals is said by scientists to increase their chances of publishing in the top journals in the future. But these journals maintain an artificial scarcity of spaces, which Neal Young and his colleagues in 2008 labelled as the "winner's curse" in their influential article. The authors likened the artificial page limits in prestigious journals to artificial scarcity in economics to restrict supply of a commodity. In the past, before the era of online journals, print page limits were limited so the scarcity of publication slots was justified; nowadays, however, it is harder to justify high rejection rates other than by the rationale that extremely low acceptance rates signal high status to successful authors.

\section{The Hierarchies in Life Science journals}

So what happens to the papers rejected from these three top journals? The traditional response was that most authors of rejected papers would aim for a lower tier of journals, with some choosing smaller specialist journals for the outlet of 
their work. Recently, however, a different mechanism of cascading the papers down the hierarchy of journals has become popular. Some journals pass the rejected papers, with the authors' permission, to what is sometimes referred to as their "sister journals," bearing the same brand. For example, the journal families of Cell, Nature, or Science now comprise smaller journals under their own brand and offer these journals as outlets for good quality work that has been rejected from the top journals. For example, with the author's permission, Science transfers papers to its sister journals Science Immunology, Science Advances, Science Robotics, or Science Signalling. The stated goal of this transfer mechanism is to help authors find a place to publish their paper as quickly and smoothly as possible. Indeed, this practice is beneficial for the authors, as their papers are published faster than they would be otherwise. For the journal families, the practice of transfers also makes good business sense, because it allows publishers to capture a greater share of the market. One of the editors I interviewed commented, "If you get a paper, review it, and reject it, the financial model tells you you've not made any money, you've spent money but you've not made any. If you can cascade it, (...) it gets published then in your open-access journal that's a bit lower, but you now monetize the submission." And, unsurprisingly, open-access journals often charge significant publication fees.

Some of the editors of smaller journals raised concerns that this system reinforces the monopoly of the biggest brands, as sister journals soak up rejected papers. The concern expressed by some editors of the middle-tier, small, specialist journals was that the papers that used to be submitted to their journals are now published in the journals owned by the three big families Cell, Nature, and Science. One journal editor commented on the power of the $\mathrm{Na}$ ture brand, "Nature is one of the most powerful brands in the world, even more powerful than most fashion brands. People flock to these journals at all costs. The name alone stands for prestige and quality and successes in research."

Undeniably, finding a place to publish a paper as quickly and smoothly as possible is important to all authors, so the trickle-down arrangements may be a good solution for authors as well as editors. And, indeed, this is what I found: some authors saw these arrangements as par for the course-they submit their paper, for example, to $\mathrm{Na}$ ture, knowing that they will probably get it into Nature Communications. However, the editors of smaller specialist journals worry about this trend, as they feel that they are being squeezed out by the big brands. While the big journals see increases in submissions, mid-tier, specialist journals (mostly with impact factors under Io) experience a fall in the numbers of submissions and see their share of the market of publications decreasing. Most editors of these smaller specialist journals would like to see their numbers rise, but as one editor pessimistically commented, "The future of this market is fighting for submissions."

\section{The "Champagne Tower" of Life Science Journals}

The metaphor that I believe best captures the hierarchical nature of science publishing is that of the champagne tower. Just as the glasses in the tower are organized in tiers, so are scientific journals, with prestigious elite journals at the top (Cell, Nature, Science) and lowest-ranked journals at the bottom. In between are various tiers of journals in decreasing order according to their impact factor. When rejected from the top tier journals, papers, like champagne, trickle down the champagne tower, metaphorically "losing their bubbles" on the way down. Journal editors sometimes express a cynical view that everything will get published somewhere, eventually. So if lower-tier journals soak up rejected papers, it is worth considering who owns these "champagne glasses"-are these lower-tier journals small specialist publications run by scientific associations, or are they journals owned by the big families? Who benefits from these arrangements, and who loses out? The practice I researched is currently common in the life sciences, but it is increasingly piloted in the social sciences. Before accepting the practice uncritically, I argue that editors of social science journals should carefully consider both its advantages and disadvantages.

DOI: http://dx.doi.org/ı0.60I7/ihe.20I8.94.10524

\section{Higher Education Journals: An Emerging Field}

\section{MaLCOLM Tight}

Malcolm Tight is professor of education at Lancaster University, UK. E-mail:m.tight@lancaster.ac.uk.

T igher education journals are, arguably, the most sig1 nificant repository for the outputs of higher education research. Therefore, it is important-whether you are a higher education researcher or someone with an interest in that research-to know something about them. How many are they? What do they focus on? Who owns them? Where are they based? How old are they? How much do they publish? Which are the best? What does the future hold?

This article summarizes the findings of an investigation into these questions, though it has to be emphasized that the answers provided are not definitive and that this is 